\title{
Biochemical Studies on Polyamine and Its Analogues
}

\section{Part I. Phagocidal Action of Enzymatically Oxidized Amines}

\author{
By Toshikazu OkI, ${ }^{\dagger}$ Haruhiko KawasakI, Koichi Ogata, Hideaki Yamada ${ }^{*}$ \\ Ichiro Tomida, ${ }^{* *}$ Tetsuo Morino** and Hiroshi Fukami** \\ Department of Agricultural Chemistry, $K$ yoto University, $K$ yoto \\ * Research Institute for Food Science, Kyoto University, Kyoto \\ ** Pesticide Research Institute, Kyoto University, $K$ yoto \\ Received June 6, 1968
}

\begin{abstract}
The phagocidal action of oxidation products of natural and synthetic amines by crystalline amine oxidase preparations has been investigated with a large variety of bacteriophages. Oxidized spermine was shown to inactivate T3, T5, T7, MS2, $\phi 80, \lambda$ (Escherichia coli); $\varepsilon^{15}$, $\varepsilon^{34}$ (Salmonella anatum); A1 (Bacillus subtilis); P465, P468, Ap85, P4 (Brevibacterium lactofermentum); I128T (Pseudomonas glycinea), I2418 (Xanthomonas phaseoli) and PK66 (Streptomyces griseus). Phages of T2, T4, T6, $\phi \times 174$ (E. coli), $\mathrm{P} 22$ (S. anatum) and M2, SP10 (B. subtilis) was not inactivated. Essentially the similar activity was observed with the oxidation products of spermidine and synthetic polyamines analogous to spermine.

The reduction of logarithmic titers of survival phages by the oxidized polyamines proceeded linearly with both incubation time and concentration of the oxidized polyamines. Then, it is conceivable that the inactivation of phages may be due to the interaction between oxidized polyamine and phagal nucleic acid.
\end{abstract}

Spermine, $\mathrm{NH}_{2}\left(\mathrm{CH}_{2}\right)_{3} \mathrm{NH}\left(\mathrm{CH}_{2}\right)_{4} \mathrm{NH}\left(\mathrm{CH}_{2}\right)_{3}-$ $\mathrm{NH}_{2}$, a naturally occurring polyamine is oxidized by beef plasma amine oxidase ${ }^{1 \sim 31}$ to the corresponding formyldiamine, $\mathrm{OHC}\left(\mathrm{CH}_{2}\right)_{2} \mathrm{NH}\left(\mathrm{CH}_{2}\right)_{4} \mathrm{NH}\left(\mathrm{CH}_{2}\right)_{2} \mathrm{CHO}$. $^{4} \quad$ The formyldiamine, which will be referred as oxidized spermine thereafter, has been known to be toxic to certain bacteria ${ }^{51}$ coliphages of T-odd series, ${ }^{61}$ plant viruses ${ }^{71}$ and Ehrlich

$\dagger$ Present address: Central Research Laboratories, Sanraku-Ocean Co., Ltd., Fujisawa.

1) J. G. Hirsh, Exptl. Mcd., 97, 345 (1953).

2) C. W. Tabor, H. Tabor and S. M. Rosenthal, J. Biol. Chem., 208, 645 (1954).

3) H. Yamada and K. T. Yasunobu, ibid,, 237, $1511(1962)$.

4) C. W. Tabor, H. Tabor and U. Bachrach, $J$. Biol. Chem., 239, 2194 (1964).

5) H. Tabor, C. W. Tabor and S. M. Rosenthal, Ann. Rev. Biochem., 30, 579 (1961).

6) U. Bachrach, C. W. Tabor and H. Tabor, Biochim. Biophys. Acta, 78, 768 (1963).

7) U. Bachrach, S. Rabina, G. Loebenstein and G. Eilon, Nature, 208, 1095 (1965). ascites cells. ${ }^{8}$ These findings have been interpreted in terms of the formation of a biologically inactive complex between oxidized spermine and nucleic acids. ${ }^{91}$

In the previous communication, we have reported briefly the chemical synthesis of the oxidized spermine as well as its homologous compounds and evaluated their phagocidal activities with various bacteriophages. ${ }^{101}$ In the present paper, we will describe the inhibitory action of enzymatically oxidized natural and synthetic amines on a large variety of phages, in more detail.

8) U. Bachrach, S. Abzug and A. Bekierkunst, Biochim. Biophys. Acta, 134, 174 (1967).

9) U. Bachrach and J. Leibovici, Biochem. Biophys. Res. Commun., 19, 357 (1965).

10) H. Fukami, I. Tomida, T. Morino, H. Yamada, T. Oki, H. Kawasaki and K. Ogata, ibid., 28, 19 (1967). 


\section{MATERIALS AND METHODS}

Phages and their hosts. Phages and their hosts used in the present work are listed in Table I. All the coliphages and phage P22 were kindly supplied by Dr. H. Ozeki, National Institute of Health, Tokyo;

Table I. Phages and Their Hosts

\begin{tabular}{|c|c|}
\hline Phage & Host \\
\hline $\mathrm{T} 2$ & Escherichia coli B \\
\hline $\mathrm{T} 3$ & " $\quad "$ \\
\hline $\mathrm{T} 4$ & $" 1$ \\
\hline T5 & $" \prime$ \\
\hline T6 & $" 1$ \\
\hline T7 & " \\
\hline$\lambda \mathrm{ch}$ & $\mathrm{K} 12 \mathrm{C} 600 \mathrm{~T} 1 r, \mathrm{~T} 5 r, \phi 80^{r}$ \\
\hline$\phi 80 \mathrm{G}$ & $\mathrm{K} 12 \mathrm{C} 600 \mathrm{~S} \mathrm{~F} \mathrm{1}^{-}, \mathrm{B}_{1}^{-}$ \\
\hline $\mathrm{MS} 2$ & K12 W2252 Hfr, Met $^{-}$ \\
\hline$\phi \times 174$ & $" 1 \quad \mathrm{C}$ \\
\hline $\mathrm{P} 22$ & Salmonella typhimurium LT2 cys 36 \\
\hline$\varepsilon^{15}$ & Salmonella anatum A1 \\
\hline$\varepsilon^{34}$ & $" \quad \quad " \mathrm{Al}\left(\varepsilon^{15}\right)$ \\
\hline SP10 & Bacillus subtilis Marburg W23 $\mathrm{SM}^{r}$ \\
\hline M2 & " " " \\
\hline A 1 & $" \quad \quad \mathrm{~K}$ \\
\hline P465 & Brevibacterium lactofermentum No. 2256 \\
\hline P468II & "I \\
\hline Ap85III & $" 1$ \\
\hline $\mathrm{P} 4$ & $\begin{array}{lll}\prime \prime & \mathrm{SM} r\end{array}$ \\
\hline $\mathrm{I} 128 \mathrm{~T}$ & Pseudomonas glycinea Coerper No. 1 \\
\hline $\mathrm{I} 2418$ & Xanthomonas phaseoli Dowson No. 24 \\
\hline PK66 & Streptomyces griseus At 106 \\
\hline
\end{tabular}

phages $\varepsilon^{15}$ and $\varepsilon^{34}$ by Dr. S. Toyama, Institute for Virus Research, Kyoto University, Kyoto; phages SP10, MS2 and M2 by Dr. H. Saito, Institute of Applied Microbiology, Tokyo University, Tokyo; phages I128T and 12418 by Dr. R. M. Numic, University of Sarajevo, Zagrebacka, Yugoslavia; phage A1 by Dr. K. Mitsugi, Central Research Laboratories, Ajinomoto Co., Ltd., Kawasaki; phage $\phi$ X174 by Dr. M. Sekiguchi, Department of Biochemistry, Kyushu University, School of Medicine, Fukuoka; phage PK66 by Dr. M. Okanishi, preserved in the Central Research Laboratories, Sanraku-Ocean Co., Ltd., Fujisawa.

Chemicals. Natural amines were products of Sigma Chemical Company. Synthetic amines analogous to spermine were prepared by the method of

11) M. Israel, J. S. Rosenfield and E. J. Modest, J. Med. Chem., 7, 710 (1964).
Israel et al.11) Highly purified amine oxidase preparations were prepared from beef plasma and the mycelial extract of Aspergillus niger by the methods of Yamada et $a l, 3,12$ ) The oxidized amines were prepared enzymatically in reaction mixtures containing $10 \sim 30 \mu$ moles of amine, $800 \sim 1500$ units of the amine oxidase, 300 units of catalase and $150 \mu$ moles of potassium phosphate buffer, $\mathrm{pH} 6.0 \sim 8.0$, in a final volume of $3.0 \mathrm{ml} .3,13,14)$ The oxidation was carried out at $30^{\circ} \mathrm{C}$ in a Warburg apparatus and usually completed within $3 \mathrm{hr}$, with the consumption of theoretical amount of oxygen.

Medium. Bacteriophages and their host bacteria were grown in the bouillon broth consisting of $1 \%$ polypeptone, $0.5 \%$ meat extract and $0.5 \% \mathrm{NaCl}$ in tap water ( $\mathrm{pH}$ 7.5). Phage PK66 and its host Streptomyces griseus At 106 were propagated in Bennett's medium ${ }^{151}$ consisting of $1 \%$ glucose, $0.2 \%$ poly peptone, $0.1 \%$ yeast extract and $0.1 \%$ meat extract in tap water ( $\mathrm{pH} 7.0$ ).

Determination of phagocidal activity. The stock suspension of phages in bouillon broth was diluted to a concentration of approximately $10^{8}$ plaque forming units (PFU) per $\mathrm{ml}$ with the dilution buffer, which was supplemented with the required amount of oxidized amine. The suspension was incubated at $30^{\circ} \mathrm{C}$. At various time intervals, an aliquot of the suspension was taken up, diluted with the dilution buffer to a concentration of approximately $10^{3} \mathrm{PFU}$ per $\mathrm{ml}$, and the number of survival phages was assayed by the double layer method of Adams.16) The date given in the results were average values of the assay carried out on two or more agar plates. Preliminary experiments revealed that the oxidized amines in the aliquot of phage suspension did not affect the growth of host cells in the semisolid agar, even at the final concentration of $1 \mathrm{~mm}$. The dilution buffer used was composed of $0.01 \mathrm{M}$ Tris- $\mathrm{HCl}$ buffer, $\mathrm{pH} 7.5$, containing $0.5 \% \mathrm{NaCl}, 0.01 \%$ $\mathrm{MgSO}_{4} \cdot 7 \mathrm{H}_{2} \mathrm{O}, 0.005 \% \mathrm{CaCl}_{2} \cdot 2 \mathrm{H}_{2} \mathrm{O}$ and $0.01 \%$ casein.

12) H. Yamada, O. Adachi and K. Ogata, Agr. Biol. Chem., 29, 649 (1965).

13) H. Yamada, H. Kawasaki, T. Oki, I. Tomida, H. Fukami and K. Ogata, Mem. Res. Inst. Food Sci., Kyoto Univ., 29, 11 (1968).

14) H. Yamada, O. Adachi and K. Ogata, Agr. Biol. Chem., 29, 864 (1965).

15) M. Okanishi and Y. Okami, J. Gen. Appl. Microbiol., 12, 207 (1966).

16) M. H. Adams, "Bacteriophages" Interscience Publishers, Inc., New York, 1959, p. 450. 


\section{RESULTS}

\section{Phagocidal action of oxidized spermine}

The phagocidal action of oxidized spermine on various phages is summarized in Table II. It was shown that the coliphages of $\mathrm{T}$-odd series were markedly inactivated by oxidized

TABLE II. EFFECT OF OXIDIZED SPERMINE ON THE VIABILITY OF VARIOUS BACTERIOPHAGES

\begin{tabular}{|c|c|c|c|}
\hline \multirow{3}{*}{ Phage } & \multicolumn{3}{|c|}{$\mathrm{PFU} / \mathrm{ml}$} \\
\hline & \multicolumn{3}{|c|}{ Incubation time (min) } \\
\hline & 0 & 5 & 90 \\
\hline $\mathrm{T} 2$ & $8 \times 10^{9}$ & $7 \times 10^{9}$ & $3 \times 10^{8}$ \\
\hline $\mathrm{T} 3$ & $8 \times 10^{5}$ & $3 \times 10^{3}$ & $<10^{2}$ \\
\hline $\mathrm{T} 4$ & $2 \times 10^{9}$ & $9 \times 10^{8}$ & $9 \times 10^{8}$ \\
\hline T5 & $3 \times 10^{8}$ & $1 \times 10^{4}$ & $<10^{2}$ \\
\hline T6 & $4 \times 10^{8}$ & $4 \times 10^{8}$ & $3 \times 10^{8}$ \\
\hline $\mathrm{T} 7$ & $6 \times 10^{8}$ & $1 \times 10^{5}$ & $6 \times 10^{3}$ \\
\hline$\lambda_{\mathrm{ch}}$ & $7 \times 10^{7}$ & $<10^{3}$ & $<10^{2}$ \\
\hline$\phi 80 \mathrm{C}$ & $1 \times 10^{8}$ & $5 \times 10^{5}$ & $<10^{2}$ \\
\hline MS2 & $3 \times 10^{9}$ & $4 \times 10^{2}$ & $<10^{2}$ \\
\hline$\phi \mathrm{Xl74}$ & $2 \times 10^{7}$ & $2 \times 10^{7}$ & $1 \times 10^{7}$ \\
\hline $\mathrm{P} 22$ & $5 \times 10^{8}$ & $5 \times 10^{8}$ & $3 \times 10^{7}$ \\
\hline$\varepsilon^{15}$ & $5 \times 10^{8}$ & $1 \times 10^{8}$ & $2 \times 10^{4}$ \\
\hline$\varepsilon^{34}$ & $1 \times 10^{8}$ & $1 \times 10^{8}$ & $4 \times 10^{5}$ \\
\hline M2 & $6 \times 10^{8}$ & $2 \times 10^{8}$ & $2 \times 10^{7}$ \\
\hline SP10 & $4 \times 10^{3}$ & $4 \times 10^{3}$ & $3 \times 10^{3}$ \\
\hline $\mathrm{Al}$ & $2 \times 10^{5}$ & - & $<10^{2}$ \\
\hline P465 & $5 \times 10^{6}$ & $2 \times 10^{3}$ & $<10^{2}$ \\
\hline P468II & $2 \times 10^{7}$ & $1 \times 10^{2}$ & $<10^{2}$ \\
\hline Ap85III & $8 \times 10^{7}$ & $3 \times 10^{3}$ & $<10^{2}$ \\
\hline $\mathrm{P} 4$ & $2 \times 10^{8}$ & $3 \times 10^{3}$ & $<10^{2}$ \\
\hline $\mathrm{Il} 28 \mathrm{~T}$ & $4 \times 10^{5}$ & $2 \times 10^{4}$ & $<10^{2}$ \\
\hline 12418 & $9 \times 10^{8}$ & $4 \times 10^{3}$ & $1 \times 10^{3}$ \\
\hline PK66 & $7 \times 10^{8}$ & $7 \times 10^{2}$ & $<10^{2}$ \\
\hline
\end{tabular}

The incubation mixture contained $0.1 \mathrm{ml}$ of the phage suspension, $0.1 \mathrm{ml}$ of oxidized spermine $(0.6$ $\mu$ moles) and $0.8 \mathrm{ml}$ of the dilution buffer, $\mathrm{pH} 7.4$. The incubation was carried out at $30^{\circ} \mathrm{C}$ for $90 \mathrm{~min}$. The number of surviors (PFU) was determined by the double agar-layer method.

spermine but that the T-even series were inactivated only slightly. Similar findings on the coliphages have been reported by Bachrach et al. ${ }^{6)}$ Other phages, MS2, $\phi 80 \mathrm{C}$, $\lambda_{\mathrm{ch}}$ (Escherichia coli), $\varepsilon^{15}, \varepsilon^{34}$ (Salmonella anatum), P465, P468II, Ap85III, P4 (Brevibacterium lactofermentum), I128T (Pseudomonas glycinea), I2418 (Xan- thomonas phaseoli), AI (Bacillus subtilis) and PK66 (Streptomyces griseus) were also inactivated by $0.6 \mathrm{~mm}$ oxidized spermine.

Effect of oxidized spermine concentration on viability of phages

Effect of the oxidized spermine concentrations on the viability of phages $\mathrm{T} 2, \mathrm{~T} 5$ and $\mathrm{P} 22$ was examined and the result is shown in Fig. 1. It was shown that the logarithmic titers of survival phages were reduced linearly with the concentration of oxidized spermine, and that the rate of inactivation varied with

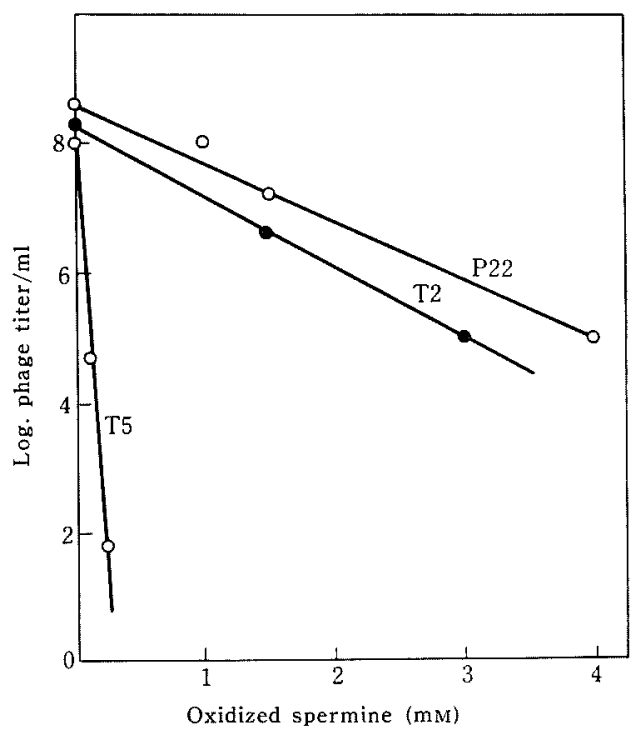

FIG. 1. Effect of Oxidized Spermine Concentrations on Inactivation of Phages T2, T5 and P22.

Phages (approximately $10^{8} \mathrm{PFU} / \mathrm{ml}$ ) were incubated with oxidized spermine in the dilution buffer, $\mathrm{pH} 7.4$, for $90 \mathrm{~min}$ at $30^{\circ} \mathrm{C}$. The number of survivors was assayed by plating on agar double layer.

phages. Phage T5 was inactivated markedly at a concentration of $0.1 \mathrm{~mm}$ and 4 logarithms of the phage titer were reduced after incubation for $90 \mathrm{~min}$. Phages T2 and P22 were, however, not inactivated at this concentration, but slightly at a rather high concentration of $4.0 \mathrm{~mm}$.

Effect of incubation time on inactivation of phages by oxidized spermine

Effect of incubation time on the inactivation 
of phages T5 and P465 by oxidized spermine was examined and the result is shown in Fig. 2. Phages were incubated at $30^{\circ} \mathrm{C}$ with oxidized spermine at a concentration of $0.6 \mathrm{~mm}$. It was

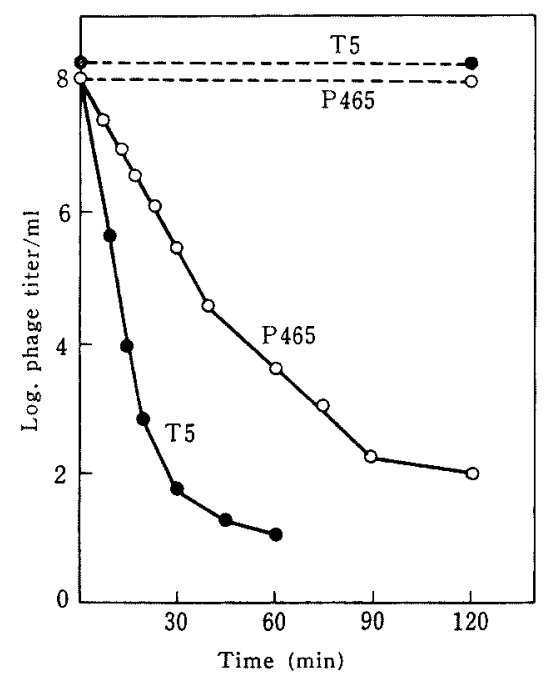

FIG. 2. Effect of Incubation Time on Inactivation of Phages T5 and P465 by Oxidized Spermine.

Phages (approximately $10^{8} \mathrm{PFU} / \mathrm{ml}$ ) were incubated at $30^{\circ} \mathrm{C}$ with oxidized spermine at a concentration of $0.6 \mathrm{mM}$. The number of survivors was determined by plating at the time specified.

- in the presence of oxidized spermine

- - - in the absence of oxidized spermine shown that the logarithmic titers of survival phages were reduced linearly with the incubation time. Phage T5 was inactivated rapidly and after incubation for $30 \mathrm{~min}$, more than 6 logarithms of the phage titer were reduced. Phage P465 was inactivated rather slowly and the same extent of reduction in titer was observed after $90 \mathrm{~min}$.

Phagocidal action of oxidation products of natural amines

Oxidation products of natural monoamines, diamines and polyamines were examined for their phagocidal activities. Monoamines and diamines were oxidized by the highly purified preparation of Aspergillus niger amine oxidase and spermidine was by the plasma amine oxidase. The results are summarized in Table III. It was shown that oxidized spermidine inactivated phages $\mathrm{T} 5$ and $\mathrm{P} 465$ similarly to oxidized spermine but that the oxidation products of other monoamines and diamines had no significant effect on the viability of phage $\mathrm{T} 5$.

Phagocidal action of oxidation product of synthetic amines

Oxidation products of synthetic diamines and polyamines were examined for their phagocidal activities and the results are

Table III. Effect of Enzymatic Oxidation Products of Natural AMINES ON THE VIABILITY OF PHAGES

Amine

None

Oxidized- $n$-butylamine

Oxidized-benzylamine

Oxidized-tryptamine

Oxidized-tyramine

Oxidized-phenetylamine

Oxidized-histamine

Oxidized-serotonin

Oxidized-putrescine

Oxidized-spermidine

Oxidized-spermine

$$
\mu \text { moles/ml }
$$$$
0
$$$$
0.82
$$$$
1.48
$$$$
1.44
$$$$
1.54
$$$$
1.47
$$$$
1.56
$$$$
\text { 1. } 48
$$$$
\text { I. } 53
$$$$
0.63
$$$$
0.60
$$

\begin{tabular}{ccc}
\multicolumn{3}{c}{$\mathrm{PFU} / \mathrm{ml}$} \\
$\mathrm{T} 2$ & $\mathrm{~T} 5$ & $\mathrm{P} 465$ \\
$3 \times 10^{7}$ & $4 \times 10^{8}$ & $2 \times 10^{8}$ \\
- & - & $1 \times 10^{8}$ \\
$2 \times 10^{7}$ & $5 \times 10^{8}$ & $2 \times 10^{8}$ \\
$6 \times 10^{6}$ & $9 \times 10^{4}$ & $6 \times 10^{7}$ \\
$2 \times 10^{7}$ & $3 \times 10^{8}$ & $6 \times 10^{5}$ \\
$2 \times 10^{7}$ & $4 \times 10^{8}$ & $2 \times 10^{8}$ \\
$2 \times 10^{7}$ & $3 \times 10^{8}$ & $4 \times 10^{5}$ \\
$1 \times 10^{7}$ & $2 \times 10^{5}$ & $2 \times 10^{7}$ \\
$2 \times 10^{7}$ & $2 \times 10^{8}$ & $2 \times 10^{8}$ \\
$2 \times 10^{7}$ & $<10^{2}$ & $4 \times 10^{2}$ \\
$5 \times 10^{6}$ & $<10^{2}$ & $<10^{2}$
\end{tabular}

Conditions of the incubation were the same as described in Table II. Natural amines were oxidized by the amine oxidases of Asp. niger and bovine plasma. 
Table IV. EFfect of Enzymatic Oxidation Products of Synthetic Spermine Analogues on the Viability of Phages

Oxidation products

None

I. $\mathrm{OHC}\left(\mathrm{CH}_{2}\right)_{m} \mathrm{NH}\left(\mathrm{CH}_{2}\right)_{n} \mathrm{NH}\left(\mathrm{CH}_{2}\right)_{m} \mathrm{CHO}$

Ia $(m=2, n=2)$

Ib $(", n=4) *$

Ic ( $(\prime, n=6)$

Id ( " , n=9)

Ie $(", n=10)$

If $(m=5, n=6)$

II. $\mathrm{R}-\left(\mathrm{CH}_{2}\right)_{2} \mathrm{CHO}$

IIa $\left(\mathrm{R}=-\mathrm{NH}\left(\mathrm{CH}_{2}\right)_{3} \mathrm{CH}_{3}\right)$

IIb $(\mathrm{R}=-\mathrm{NHCH}-\mathrm{Ph})$

IIc $\left(\mathrm{R}=-\mathrm{N}-(\mathrm{Ph})_{2}\right)$

IId $(\mathrm{R}=-\mathrm{N} \quad \mathrm{O})$ $\mu \mathrm{mole} / \mathrm{ml}$

0

0.6

0.6

0.6

0.5

0.5

0.4

0.5

0.5

1.0

0.6

$\begin{array}{ll}\text { T2 } & \mathrm{PFU} / \mathrm{ml} \\ 3 \times 10^{7} & \begin{array}{c}\mathrm{T} 5 \\ 4 \times 10^{8}\end{array} \\ 3 \times 10^{7} & <10^{2} \\ 5 \times 10^{6} & <10^{2} \\ 5 \times 10^{6} & <10^{2} \\ - & <10^{2} \\ - & <10^{2} \\ - & 2 \times 10^{5} \\ & 3 \times 10^{8} \\ - & 3 \times 10^{4} \\ 2 \times 10^{7} & 2 \times 10^{8} \\ - & 2 \times 10^{8} \\ 2 \times 10^{7} & \end{array}$

Condition of the incubation were the same as described in Table II. Oxidized polyamines of Ia, Ib and Ic were obtained with the plasma amine oxidase, and others were with the Asp. niger amine oxidase.

* Oxidized spermine

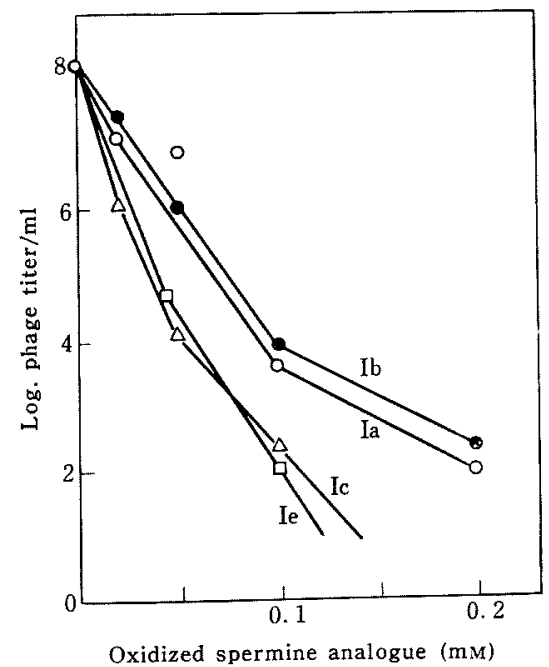

FIG. 3. Effect of Oxidized Spermine Analogues on the Viability of Phage T5.

Conditions of the incubation were the same as described in Fig. 1. The oxidized spermine analogues used were the same as described in Table III.

summarized in Table IV. The synthetic polyamines, N,N'-bis-(3-aminopropyl)-ethane-1,2diamine (Ia) and -hexane-1,6-diamine (Ic), were oxidized by the plasma amine oxidase and the other diamines and polyamines were by the Aspergillus niger amine oxidase. It was shown that all the oxidized polyamines analogous to oxidized spermine inactivated phage T5 markedly and that the oxidation products of alkyl and aryl diamines, however, were inert. The phagocidal activity of oxidized spermine analogues was observed to be great in proportion to chain length. As shown in Fig. 3, the analogue with 10 carbon chain inactivated phage T5 more rapidly at the low concentration than oxidized spermine with 4 carbon chain.

\section{DISCUSSION}

The phagocidal action of enzymatically oxidized spermine was first demonstrated by Bachrach et $a l^{61}{ }^{6}$ with coliphages of the $\mathrm{T}$ series. It has been reported that phages of the T-odd series were markedly inactivated by oxidized spermine but the T-even phages were not affected. The phagocidal action of oxidized spermine was confirmed in the present work with a large variety of bacteriophages. It was found that, in addition to T-odd phages, other phages, MS2, $\phi 80 \mathrm{C}$, $\lambda_{\text {ch }}$ 
(Escherichia coli), $\varepsilon^{15}, \varepsilon^{34}$ (Salmonella anatum), P465, P468II, Ap85III, P4 (Brevibacterium lactofermentum), II28T (Pseudomonas glycinea), I2418 (Xanthomonas phaseoli), A1 (Bacillus subtilis) and PK66 (Streptomyces griceus) were inactivated, but $\phi \times 174$ (E. coli), P22 (S. anatum) and M2, SP10 (B. subtilis) were not inactivated. These difference in the phagocidal spectrum may be explained by the different sensitibity of phages to oxidized spermine. Coliphages of the $\mathrm{T}$-even series have been reported to be less permeable to external factors. ${ }^{17 \sim 19}$ l $\mathrm{It}$ has been also reported that oxidized spermine exerts its phagocidal activity by penetrating into the phage. ${ }^{201}$ Then the difference in phage permeability may account for variation in susceptibility. On the other hand, the Teven phages, but not the T-odd phages, have been reported to contain high concentration of polyamines, ${ }^{19,211}$ which bind with phagal nucleic acids, via electrostatic binding, to form the stable complexes and are not exchangeable with ${ }^{14} \mathrm{C}$-polyamines added to the crude lysate. Therefore, polyamines may protect the $T$-even phages from the inactivation by oxidized spermine.

17) T. F. Anderson, C. Rapapport and N. A. Muscatine, Ann. Inst. Pasteur, 84, 5 (1953).

18) J. J. Helprin and C.W. Hiatt, J. Bact., 77, 502 (1959).

19) B. N. Ames and D. T. Dubin, J. Biol. Chem., 235, 769 (1960).

20) U. Bachrach and J. Leibovici, J. Mol. Biol., 19, $120(1966)$

21) B. N. Ames, D. T. Dubin and S. M. Rosenthal, Science, 127, 814 (1958).
The results presented in this paper show that the oxidized polyamines are considerably more toxic to bacteriophage than a number of other aldehydes. Oxidation products of natural monoamines and diamines by the Aspergillus niger amine oxidase did not affect the viability of phages, even at the considerably high concentrations. The reduction of logarithmic titers of sensitive phages by the oxidized polyamines proceeded linearly with both incubation time and concentration of the oxidized polyamines. It is conceivable that the inactivation is due to the chemical interaction between the oxidized polyamines and phagal nucleic acid. The nature of the interaction of oxidized polyamines with phagal nucleic acid is not known in detail. However, the results obtained from the experiment with various oxidized spermine analogues indicate that this interaction may involve two classes of binding, and that the groups of the terminal - $\mathrm{CHO}$ and the internal $-\mathrm{NH}\left(\mathrm{CH}_{2}\right)_{n}$ $\mathrm{NH}$ - in the analogues are concerned in the interaction. It seems likely that the $-\mathrm{NH}\left(\mathrm{CH}_{2}\right)_{n} \mathrm{NH}-$ group binds to the acidic site of phagal nucleic acid, via electrostatic binding, and that - $\mathrm{CHO}$ group binds to the amino group of the purine and pyrimidine, via covalent binding.

Acknowledgment. The authors wish to express their sincere thanks to Prof. T. Hata, Prof. M. Nakajima and Prof. Y. Morita, Kyoto University, for their interest and suggestion during the course of this work. 